\title{
Non-pyrolyzed cobalt-porphyrin cathode catalyst on carbon support as an efficient electrocatalyst for oxygen reduction reaction in basic medium
}

\author{
Charlene Donamae P. Cac ${ }^{1}$, Maria Krisandra L. Mendoza ${ }^{2}$, E Bernard John V. Tongol ${ }^{1-3 *}$ \\ ${ }^{1}$ Department of Chemistry, College of Science; ${ }^{2}$ Graduate School; ${ }^{3}$ Research Center for the Natural \\ and Applied Sciences, University of Santo Tomas, 1015 Manila, Philippines
}

\begin{abstract}
Owing to their high energy efficiency, reduced pollution, and minimal maintenance cost, fuel cells have been regarded as one of the most promising energy conversion devices. The commonly used effective electrocatalysts are platinum-based materials. The development of fuel cell electrodes with non-noble metal catalysts to lessen the use of Pt-based materials has been the focus of this study. The cathode catalysts were synthesized using the sodium borohydride reduction method. Catalyst inks were prepared and subjected to electrochemical characterization that included linear sweep voltammetry (LSV) and cyclic voltammetry (CV). Optimization of the metal loading and metal salt shows that the non-precious metal catalyst, 20\% cobalt porphyrin (2,3,7,8,12,13,17,18-Octaethyl-21H, 23H-porphine cobalt (II)) supported on carbon black (CoP/C), gave the highest catalytic activity having a current density of $2.23 \mathrm{~mA} \mathrm{~cm}^{-2}$ compared to the commercially available 20\% Pt/C (Premetek, USA) $\left(1.46 \mathrm{~mA} \mathrm{~cm}^{-2}\right)$ in basic medium. The retained current for the CoP/C was $58.15 \%$ while for the $20 \% \mathrm{Pt} / \mathrm{C}$ catalyst (Premetek (USA), it was $21.23 \%$. The electrochemical impedance spectroscopy (EIS) showed enhanced electron transfer kinetics for CoP/C than the commercially available 20\% Pt/C (Premetek, USA). The morphological and surface characterization were obtained using scanning electron microscopy (SEM) and energy dispersive X-ray (EDX) analysis that confirmed the 20\% metal loading of the catalyst.
\end{abstract}

Keywords: cobalt porphyrin, cathode catalyst, fuel cell, oxygen reduction reaction

\section{INTRODUCTION}

A fuel cell is an electrochemical device that converts chemical energy to electrical energy via chemical reaction [1]. Fuel cell technologies have the potential to contribute to a sustainable and emission-free transport and energy system. The ascendance of electrocatalysts for oxygen

*To whom correspondence should be addressed: bvtongol@ust.edu.ph reduction reaction (ORR) in fuel cells puts a high premium on the development of efficient catalysts to improve the overall performance of fuel cells. The cathode reaction for oxygen reduction proceeds through a multistep electron transfer, leading to sluggish kinetics and a high overpotential [2]. For fuel cells, effective electrocatalysts, such as the commonly used Pt-based materials, are needed to reduce the overpotential and expedite the ORR, through a direct four-electron transfer process. However, 
because of numerous disadvantages like the high price, intolerance to fuel crossover, and instability [3], Pt-based catalysts hindered the broad commercialization.

Recent researches on alternative non-noble ORR catalysts, including the use of cobalt phthalocyanines and cobalt porphyrins, have gained attention. Also, adsorbed $\mathrm{Fe}$ and Co phthalocyanines on different carbon nanotubes have been extensively studied [4]. In a metallophthalocyanine, the central metal ion has little to no effect on the ionization potential of the molecule. Conversely, the central ion metal in metalloporphyrins greatly affects the ionization potential [5], making it possible to enhance their activity with the use of the right metal. For porphyrin systems, cobalt derivatives were investigated to have higher ionization potential and higher reactivity [6]. Unpyrolyzed transition metal macrocycles with cobalt as the central metal atom have shown to be more stable than the corresponding iron complexes, but generate high peroxide yields with $n$ (number of electrons exchanged per oxygen molecule) values of 2-2.5 compared to Fe-based of $n=$ 3.1-3.4 [7] Research efforts have been directed towards preparation of transition metal macrocycle materials with pyrolysis upon the discovery of the enhancement of electrochemical activity and stability [8]. However, Wieckowski's group [9] pointed that pyrolyzed porphyrins are no longer porphyrins. The structure of the active site generated during pyrolysis has been the subject of some debate.

Carbon is widely used in the catalytic processes due to its unique characteristics that make it an ideal material for use in fuel cells. Support materials are classified as carbon black, carbon nanotubes and fibers, mesoporous carbon, multi-layer graphene (undoped and doped with metal nanoparticles) and reduced graphene oxide [10]. Of the carbon materials, carbon blacks are the cheapest and most sustainable, and can have important implications for the commercialization of fuel cells in the future [11].

In this study, the catalytic activity of a synthesized non-pyrolyzed cobalt-porphyrin (CoP) cathode catalyst on carbon support was investigated for ORR in basic medium and compared with PtCo/C catalyst [12]. Pt-Co alloy nanoparticles are one of the most intensively studied fuel cell electrocatalysts for acidic polymer electrolyte membrane fuel cell (PEMFCs) due to the enhanced initial ORR activity. In contrast, there are only few research works on Pt-Co in alkaline fuel cells [12]. To preserve the macrocyclic structure, no pyrolysis and post synthetic treatment was done on the CoP catalyst [8]. The catalyst was evaluated in basic medium [13] for possible application in alkaline direct ethanol fuel cell (DEFC) [14].

\section{EXPERIMENTAL}

Materials and chemicals. All reagents were of analytical grade and were used as received. CoP, $\mathrm{H}_{2} \mathrm{PtCl}_{6} \bullet 6 \mathrm{H}_{2} \mathrm{O}(\geq 37.5 \%)$, N,N-Dimethylformamide (99.8\%), and $\mathrm{NaBH}_{4}$ were purchased from Sigma Aldrich Co. (Singapore). The carbon black (Cabot, USA), NaOH (RCI Labscan, Thailand), and $5 \%$ by weight Nafion ${ }^{\circledR}$ D521 (Ion Power Inc., USA) were also used as received. The ultrapure water (Resistivity $=18.2 \mathrm{M} \Omega \mathrm{cm}$ ) was obtained from a Millipore water purification system (Millipore Co., USA).

Synthesis of cathode catalysts. The catalysts were synthesized by a chemical method using $\mathrm{NaBH}_{4}$ as the reducing agent. All of the glasswares were acid washed with concentrated sulfuric acid before use. The carbon black support was dispersed in $32 \mathrm{~mL}$ ultrapure water with ultrasonic agitation. The amount of CoP salt added was adjusted so that the metal-oncarbon loading was $20 \mathrm{wt} \%$. This was added to the mixture and stirred for an hour at $80^{\circ} \mathrm{C}$. Its $\mathrm{pH}$ was adjusted to $\sim 11$ using $0.5 \mathrm{M} \mathrm{NaOH}$ solution and the addition of excess $\mathrm{NaBH}_{4}$ 
facilitated the reduction. The mixture was stirred for another hour and its powder was recovered by filtration, washed with ultrapure water, and dried. The same procedure was followed for the synthesis of $\mathrm{PtCo} / \mathrm{C}$ by using hexachloroplatinic acid and cobalt(II) chloride solutions adjusted to different metal ratio with metal-on-carbon loading of $20 \mathrm{wt} \%$.

Surface characterization. The SEM (JEOL JSM 5310) and EDX (OXFORD) were used to evaluate the surface morphology of the synthesized CoP/ $\mathrm{C}$ catalyst. Both characterizations were done with an accelerating voltage of $15 \mathrm{kV}$.

\section{Electrode preparation and electrochemical} measurements. The electrocatalytic activity of the synthesized cathode catalysts towards ORR was measured using cylic voltammetry (CV) and linear sweep voltammetry (LSV). The stability was studied using chronoamperometry (CA) while the ORR kinetics was examined using electrochemical impedance spectroscopy (EIS). A three-electrode cell system composed of the modified glassy carbon electrode as the working electrode, $\mathrm{Ag} \mid \mathrm{AgCl}$ as the reference electrode, and the Pt wire as the counter electrode. The working electrode was prepared by dropcasting $20 \mu \mathrm{L}$ of the catalyst ink on the surface of the glassy carbon electrode. The catalyst ink was prepared by dispersing $1 \mathrm{mg}$ of the catalyst powder in $980 \mu \mathrm{L} \mathrm{N}, \mathrm{N}$-dimethylformamide (DMF) and $20 \mu \mathrm{L}$ Nafion ${ }^{\circledR}$ with ultrasonic agitation.

The CV measurements were performed with a scan rate of $50 \mathrm{mV} / \mathrm{s}$ with a potential range from -0.90 to $0.40 \mathrm{~V}$ for 20 cycles while the potential range for LSV was from -0.70 to $-0.05 \mathrm{~V}$. The $0.5 \mathrm{M} \mathrm{NaOH}$ electrolyte in the cell was bubbled with oxygen gas for $15 \mathrm{~min}$. The effects of varying the metal ratio and the metal loading on the ORR activity were studied for $\mathrm{PtCo} / \mathrm{C}$ catalyst. The optimized parameters were then used to study the ORR activity of CoP/C catalyst.
The same three-electrode system set-up and potentiostat (EDAQ) were used for CA with the potential held at $-100 \mathrm{mV}$ for $3000 \mathrm{~s}$. The EIS (Biologic VSP-300) was performed with a frequency range from $700 \mathrm{MHz}$ to $100,000 \mathrm{mHz}$ and an AC amplitude of $100 \mathrm{mV}$.

\section{Results AND Discussion}

Effect of varying the metal ratio of PtCo/C. In $0.5 \mathrm{M} \mathrm{NaOH}$, the $\mathrm{CV}$ profile (Fig. 1) for $\mathrm{PtCo} / \mathrm{C}$ showed the hydrogen desorption-adsorption region at $\sim-0.9$ to $-0.7 \mathrm{~V}$ (vs. $\mathrm{Ag} / \mathrm{AgCl}$ ), indicative of $\mathrm{Pt}$ atoms on the catalyst surface [12]. In the case of PtCo alloys, the presence of a redox pair located at around $-0.2 /-0.5 \mathrm{~V}$ (vs. $\mathrm{Ag} / \mathrm{AgCl}$ ) can be observed and can be assigned to a redox process involving $\mathrm{Co}(\mathrm{OH})_{2} / \mathrm{Co}(\mathrm{OH})_{3}$ species in close contact to surface Pt atoms [15]. The broad anodic peak at around $0.0-0.10 \mathrm{~V}$ could be attributed to metal oxide formation while the cathodic peak at around $-0.2 \mathrm{~V}$ corresponds to the Pt and Co site of ORR.

Based on the CV profile in Fig. 1, 50:50 PtCo catalyst gave the highest cathodic current densities among the three catalysts prepared with varying metal ratios. The $\sim 50: 50$ PtCo catalyst exhibits the largest kinetic current density because it exhibited the better mass-

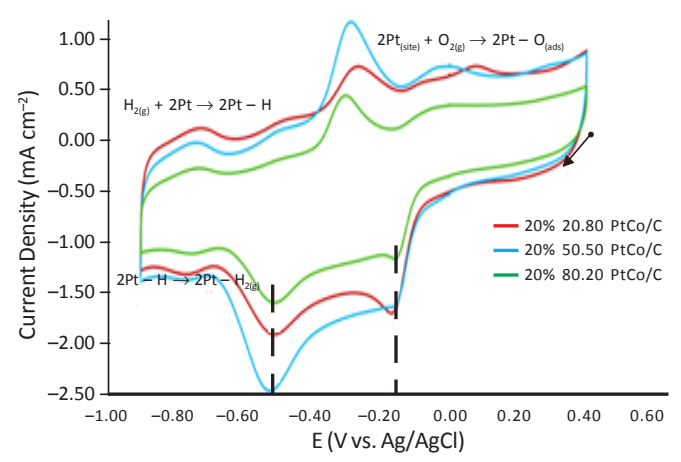

Figure 1. Cyclic voltammogram (20 th $c y c l e)$ of $\mathrm{PtCo} /$ $\mathrm{C}$ catalysts with varying metal ratio (Pt:Co) in $0.5 \mathrm{M} \mathrm{NaOH}$ electrolyte with a potential range from -0.90 to $0.40 \mathrm{~V}$ (vs. $\mathrm{Ag} / \mathrm{AgCl}$ ) at a scan rate of $50 \mathrm{mV} / \mathrm{s}$. 
specific activity [15]. This suggests that the alloying effect between Pt and Co atoms has a substantial impact on the ORR kinetics [16]. The volcano-type relationship between the alloy compositions and their corresponding ORR activity are generally accepted in binary alloy systems and usually attributed to the changes in surface structures including geometric structure (ensemble effect) and electronic structure of Pt (electronic effect), which affect the ORR kinetics [16].

\section{Effect of varying the metal loading of PtCo/C.}

The effect of metal loading was studied by maintaining a constant optimized ratio of 50:50 PtCo. Figure 2A shows the CV profile depicting the effect of varying the metal loading of the different catalysts. The peak assignments and mechanisms governing the $\mathrm{CV}$ profile in Fig. 2 are similar with Fig. 1. However, the only difference in this CV profile is that the specific current density is plotted against the potential. This was done to properly evaluate the activity of the catalysts taking into consideration their different loadings because the highest metal loading automatically gives the highest current peak.

Shown in Fig. 2B is the LSV profile depicting the effect of metal loading, i.e. a plot of specific current density against the potential. The

A

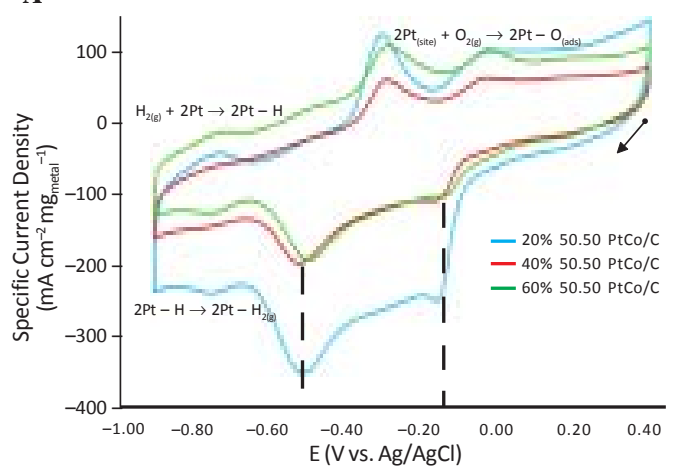

highest current peak among the three various catalysts is observed with the $20 \%$ metal loading. Only at lower metal loadings will the catalytic activity be the most effective because at higher metal loadings, a possible spillover of hydrogen on the carbon support could be obtained [17]. Therefore, the trend coincides with what was shown in the linear sweep voltammogram. The $20 \% 50: 50 \mathrm{PtCo} / \mathrm{C}$ is the optimized metal loading of the bimetallic catalyst. These optimized parameters were used to prepare the $20 \% \mathrm{CoP} / \mathrm{C}$ catalyst.

LSV Studies of the cathode catalysts. The observable peak for CoP/C occurs at a potential of $\sim-0.20 \mathrm{~V}$ (Fig. 3) which could be assigned to cobalt center redox reaction of surface adsorbed CoP [18]. The reaction sequence of the oxygen and subsequent hydrogen peroxide electroreduction [19] catalyzed by CoP (or P$\mathrm{Co}$ ) in alkaline solution could be suggested as follows :

$$
\begin{aligned}
& \mathrm{P}-\mathrm{Co}^{\mathrm{II}}+\mathrm{OH}^{-}+\mathrm{O}_{2}=\mathrm{P}-\mathrm{Co}^{\mathrm{II}}-\mathrm{O}_{2}+\mathrm{OH}^{-} \\
& \mathrm{P}-\mathrm{Co}^{\mathrm{II}}-\mathrm{O}_{2}+\mathrm{H}_{2} \mathrm{O}+2 \mathrm{e}^{-}=\mathrm{P}-\mathrm{Co}^{\mathrm{II}}-\mathrm{OH}^{-}+\mathrm{HO}_{2}^{-} \\
& \mathrm{P}-\mathrm{Co}^{\mathrm{II}}-\mathrm{OH}^{-}+\mathrm{HO}_{2}^{-}=\mathrm{P}_{-} \mathrm{Co}^{\mathrm{II}}-\mathrm{HO}_{2}^{-}+\mathrm{OH}^{-} \\
& \mathrm{P}-\mathrm{Co}^{\mathrm{II}}-\mathrm{HO}_{2}^{-}+\mathrm{H}_{2} \mathrm{O}+2 \mathrm{e}^{-}=\mathrm{P}-\mathrm{Co}^{\mathrm{II}}-\mathrm{OH}^{-}+2 \mathrm{OH}
\end{aligned}
$$

Quantitatively assessing these peaks in Table 1 , the $20 \% \mathrm{CoP} / \mathrm{C}$ catalyst obtained the highest current density of $2.23 \mathrm{~mA} \mathrm{~cm}{ }^{-2}$, followed by $20 \% \mathrm{Pt} / \mathrm{C}$ (Premetek, USA) with a current density

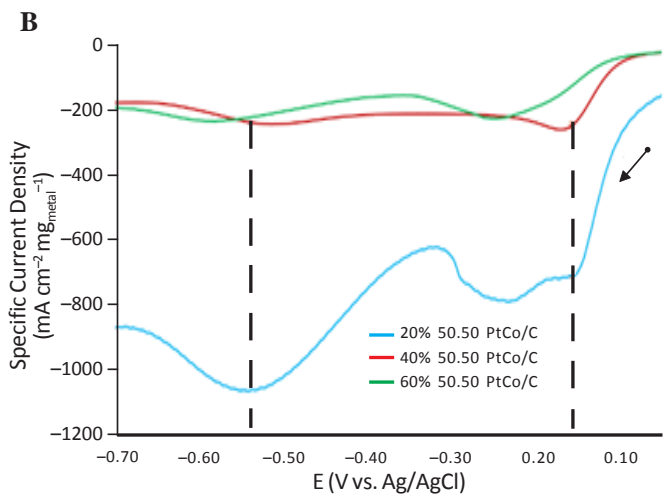

Figure 2. (A) CV and (B) LSV studies of PtCo/C catalysts with varying metal loading in $0.5 \mathrm{M}$ NaOH electrolyte with a potential range from -0.90 to $0.40 \mathrm{~V}$ (vs. Ag/AgCl) at a scan rate of $50 \mathrm{mV} / \mathrm{s}$ for 20 cycles for (A) and a potential range from -0.70 to $-0.05 \mathrm{~V}$ and a scan rate of $50 \mathrm{mV} / \mathrm{s}$ for (B) 


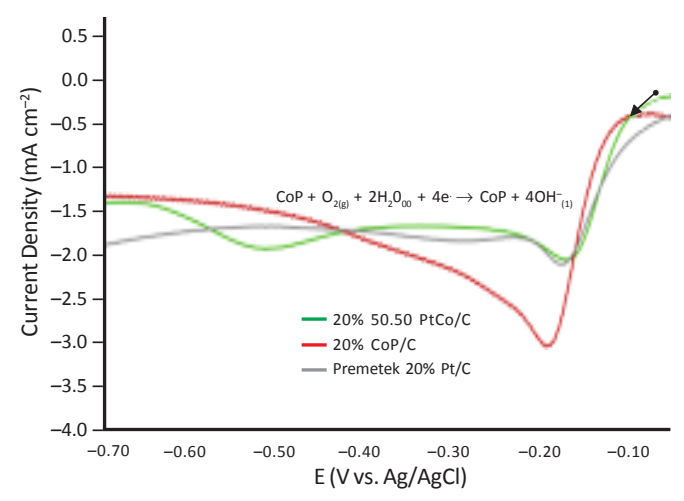

Figure 3. Linear sweep voltammogram of $\mathrm{PtCo} / \mathrm{C}$ and $\mathrm{CoP} / \mathrm{C}$ catalysts in $0.5 \mathrm{M} \mathrm{NaOH}$ electrolyte with a potential range from -0.70 to $-0.05 \mathrm{~V}$ (vs. $\mathrm{Ag} / \mathrm{AgCl}$ ) at a scan rate of $50 \mathrm{mV} / \mathrm{s}$.

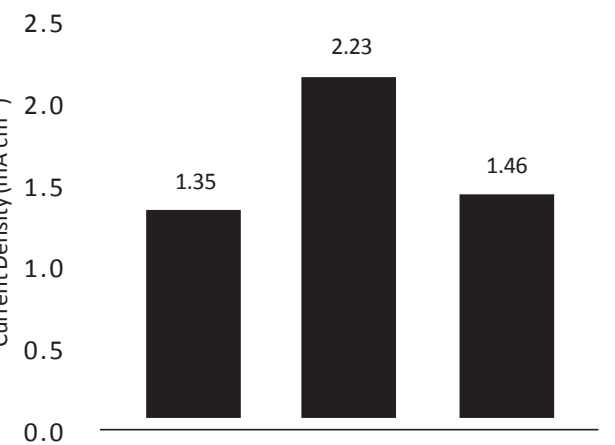

Figure 4. Comparison of the synthesized catalysts in terms of current density.

of $1 . \mathrm{mA} \mathrm{cm}^{-2}$, then, $20 \% \mathrm{PtCo} / \mathrm{C}$ bimetallic catalyst with a current density of $1.35 \mathrm{~mA} \mathrm{~cm}^{-2}$.

This pronounced high catalytic activity of $\mathrm{CoP} /$ $\mathrm{C}$ is due to the fact that the porphyrin is an $\mathrm{N}_{4^{-}}$ macrocycle which is found to be active in catalyzing reduction of oxygen [18] due to the interaction between oxygen and the central metal ion, Co, based on the model of molecular orbital theory. The carbon support and $\mathrm{N}_{4}$-macrocycle of the porphyrin interact mainly by non-covalent interactions such as the axial coordination and the $\pi-\pi$ interaction [8]. The nature of carbon support affected the performance of catalysts in fuel cells [9]. Furthermore, the $\mathrm{N}_{4}$-complex of
Table 1. Electrochemical characteristics of the cathode catalysts

\begin{tabular}{|c|c|c|}
\hline Cathode Catalysts & $\begin{array}{c}\text { Current } \\
\text { (mA) }\end{array}$ & $\begin{array}{c}\text { Current } \\
\text { Density } \\
\left.(\mathrm{mA} \mathrm{cm})^{-2}\right)\end{array}$ \\
\hline 20\% 50:50 PtCo/C & 0.09530 & 1.35 \\
\hline $20 \% \mathrm{CoP} / \mathrm{C}$ & 0.15760 & 2.23 \\
\hline 20\% Pt/C (Pemetek, USA) & 0.10340 & 1.46 \\
\hline
\end{tabular}

Table 2. Repeatablity study for the synthesized $\mathrm{CoP} / \mathrm{C}$ catalyst $(n=3)$.

\begin{tabular}{|c|c|c|c|}
\hline Trial & $\begin{array}{c}\text { Current } \\
\text { (mA) }\end{array}$ & \multicolumn{2}{|c|}{$\begin{array}{c}\text { Current Density } \\
\left.(\mathrm{mA} \mathrm{cm})^{-2}\right)\end{array}$} \\
\hline 1 & 0.1576 & \multicolumn{2}{|c|}{2.23} \\
\hline 2 & 0.1482 & \multicolumn{2}{|c|}{2.10} \\
\hline 3 & 0.1543 & \multicolumn{2}{|c|}{2.18} \\
\hline & & Mean $=2.17$ & $\begin{array}{l}\mathrm{SD}=0.05508 \\
\% \mathrm{RSD}=2.54\end{array}$ \\
\hline
\end{tabular}

the porphyrin has a conjugated $\pi$-electron system, unlike uncomplexed bimetallic PtCo/C and 20\% Pt/C (Premetek, USA), which seems to be a prerequisite for activation of the oxygen molecule; thus, the observable increase in the current density of the CoP/C. For visual purposes, the comparison of these catalysts is presented in Fig. 4.

After comparing the catalytic activity of the CoP/ $\mathrm{C}$ with other cathode catalysts, its repeatability was tested through the evaluation of the three trials conducted in the experiment. Table 2 gives the tabulated data of the results of the trials and the obtained mean is $2.17 \mathrm{~mA} \mathrm{~cm}^{-2}$. Having a low value of SD (0.05508) and \%RSD (2.54), it can be inferred that the trials are repeatable.

Stability study. In order to further study the electrochemical stability of carbon-supported CoP, CA was performed. The chronoamperometric responses of Pt/C- (Premetek, USA) and CoP/C-modified glassy carbon electrodes in $0.5 \mathrm{M} \mathrm{NaOH}$ electrolyte with a potential held at $-100 \mathrm{mV}$ for $3000 \mathrm{~s}$ are shown in Fig. 5. The current densities were negative because these are reduction reactions. The current densities 
for both 20\% Pt/C catalyst (Premetek, USA) and $20 \% \mathrm{CoP} / \mathrm{C}$ started to stabilize at $500 \mathrm{~s}$. The current retention is higher for CoP/C (58.15\%) than the 20\% Pt/C (Premetek, USA) (21.23\%).

EIS study. Electrochemical impedance is usually measured by applying an AC potential to an electrochemical cell and then measuring the current through the cell [20]. Like resistance, impedance is a measure of the ability of a circuit to resist the flow of electrical current. The EIS analysis of 20\% Pt/C (Premetek, USA) and 20\% $\mathrm{CoP} / \mathrm{C}$ is shown in Fig. 6. The semicircle and the linear region of the EIS spectra corresponding to the charge transfer and mass transfer

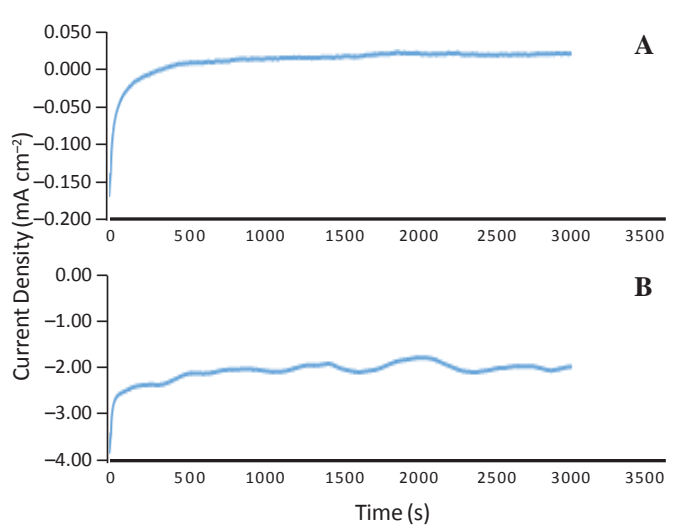

Figure 5. Chronoamperometry profiles of (A) 20\% $\mathrm{Pt} / \mathrm{C}$ (Premetek, USA) and (B) 20\% CoP/C in $0.5 \mathrm{M} \mathrm{NaOH}$ electrolyte with a potential held at $-100 \mathrm{mV}$ for $3000 \mathrm{~s}$.

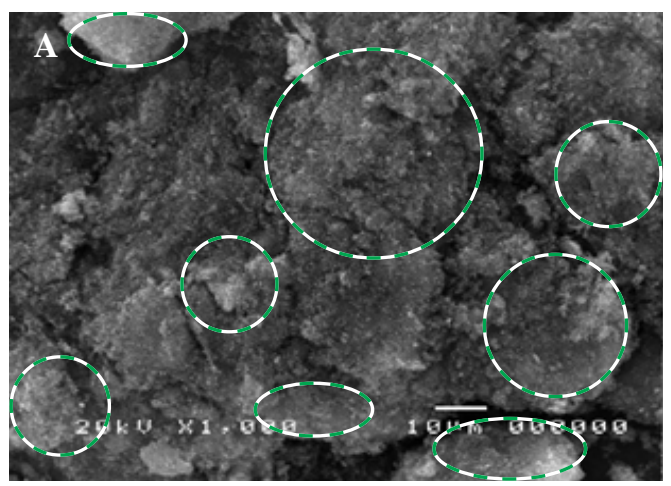

processes are quite visible at the high frequency and low frequency range, respectively [21]. It was found that the diameter of the semi-circle for $20 \% \mathrm{CoP} / \mathrm{C}$ is smaller than $20 \% \mathrm{Pt} / \mathrm{C}$ (Premetek, USA), indicating enhanced electron transfer in $\mathrm{CoP} / \mathrm{C}$ than $\mathrm{Pt} / \mathrm{C}$ in basic medium.

Surface characterization of CoP/C. The use of SEM and EDX determines its surface morphology and elemental composition, respectively. Figure 7 shows a rough surface morphology with bright particles which could be attributed to Co particles in CoP/C. The surface formed aggregates, indicating that these metallic particles may come from the mixed CoP/

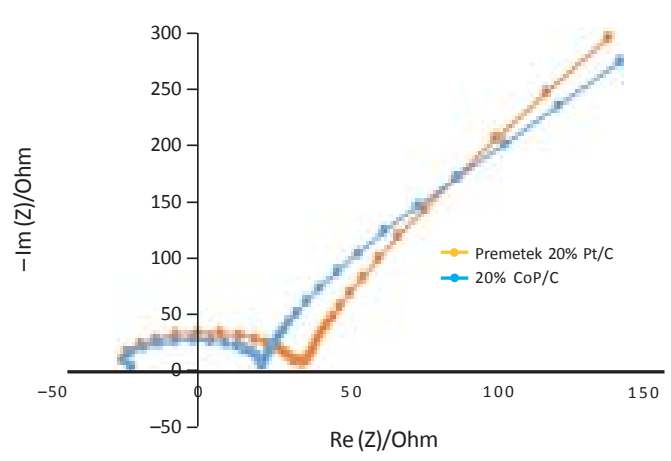

Figure 6. EIS analysis of $20 \% \mathrm{Pt} / \mathrm{C}$ (Premetek, USA) and $20 \% \mathrm{CoP} / \mathrm{C}$.

Figure 7. SEM images of the $20 \% \mathrm{CoP} / \mathrm{C}$ at $(\mathrm{A}) \times 1000$ and $(\mathrm{B}) \times 7500$ magnifications. 

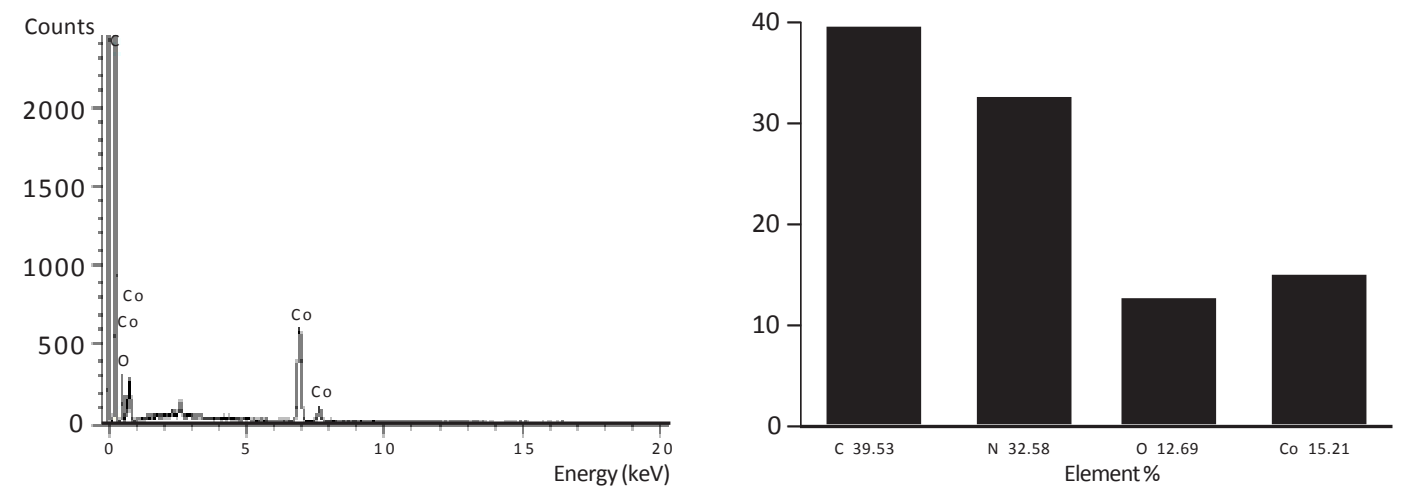

Figure 8. EDX analysis of the $20 \% \mathrm{CoP} / \mathrm{C}$

C composite. A similar surface morphology was obtained by Sun and co-workers [22] for Co porphyrin before heat treatment at $1000^{\circ} \mathrm{C}$. The EDX analysis in Fig. 8 confirmed the presence of Co metal at $\sim 15 \%$ metal loading.

\section{CONCLUSION}

In this study, a carbon-supported PtCo and Co porphyrin catalysts were prepared through the sodium borohydride reduction method. The effects of metal ratio and metal loading on the ORR activity were studied for $\mathrm{PtCo} / \mathrm{C}$ catalyst which gave optimum values of 50:50 Pt:Co metal ratio and $20 \%$ metal loading. The metal loading of $20 \%$ was used for CoP/C catalyst and its ORR activity was compared with the synthesized $20 \%$ $50: 50 \mathrm{PtCo} / \mathrm{C}$ and the commercially available $\mathrm{Pt} /$ C (Premetek, USA). CV and LSV studies showed that $20 \% \mathrm{CoP} / \mathrm{C}\left(2.23 \mathrm{~mA} \mathrm{~cm}{ }^{-2}\right)$ gave higher electrocatalytic activity towards ORR compared to commercially available $20 \% \mathrm{Pt} / \mathrm{C}\left(1.46 \mathrm{~mA} \mathrm{~cm}^{-2}\right)$ in basic medium. Chronoamperometry revealed a more stable CoP/C catalyst with a higher current retention of 58.15\% compared to $21.23 \%$ for $20 \% \mathrm{Pt} / \mathrm{C}$ (Premetek, USA) catalyst. EIS analysis showed that the diameter of the semicircle for $20 \%$ CoP/C is smaller than $20 \% \mathrm{Pt} / \mathrm{C}$ (Premetek, USA), indicating enhanced electron transfer in $\mathrm{CoP} / \mathrm{C}$ than $\mathrm{Pt} / \mathrm{C}$ in basic medium. The SEM of CoP/C revealed a rough surface morphology with bright protrusions. EDX analyses confirmed the presence of Co metal with $\sim 15 \%$ metal loading in the catalyst.

\section{AcKNOWLedgement}

This research work was financially supported by the Department of Science and Technology - Philippine Council for Industry, Energy and Emerging Technology Research and Development (DOST-PCIEERD).

\section{REFERENCES}

[1] Wu JB, Yang H. Platinum-based oxygen reduction electrocatalysts. Accounts of Chemical Research 2013; 46:1848-57.

[2] Kruusenberg I, Matisen L, Shah Q, Kannan AM, Tammaveski K. Non-platinum cathode catalysts for alkaline membrane fuel cells. International Journal of Hydrogen Energy 2012; 37:4406-12.

[3] Nallathambi V, Lee JW, Kumaraguru SP, Wu G, Popov BN. Development of high performance carbon composite catalyst for oxygen reduction reaction in PEM Proton Exchange Membrane fuel cells. Journal of Power Sources 2008; 183:3442.

[4] Morozan A, Campidelli S, Filoramo A, Jousselme $B$, Palacin S. Catalytic activity of cobalt and iron phthalocyanines or porphyrins supported on different carbon nanotubes towards oxygen reduction reaction. Carbon 2011; 49(14):4839_ 47.

[5] Zhang J (Ed.). PEM fuel cell electrocatalysts and catalyst layers, p. 89. (Springer London, 2008). 
[6] Shi Z, Zhang J. Density functional theory study of transitional metal macrocyclic complexes' dioxygen-binding abilities and their catalytic activities toward oxygen reduction reaction. Journal of Physical Chemistry C 2007; 111:708490.

[7] Kiros Y. Metal porphyrins for oxygen reduction in PEMFC. International Journal of Electrochemical Science 2007; 2:285-300.

[8] Goubert-Renaudin S, Zhu X, Wieckowski A. Synthesis and characterization of carbonsupported transition metal oxide nanoparticles - Cobalt porphyrin as catalysts for electroreduction of oxygen in acids. Electrochemistry Communications 2010; 12:1457-61.

[9] Cheng N, Kemna C, Goubert-Renaudin S, Wieckowski A. Reduction reaction by porphyrinbased catalysts for fuel cells. Electrocatalysis 2012; 3:238-51.

[10] Sharma S, Pollet B. Support materials for PEMFC and DMFC electrocatalysts - A review. Journal of Power Sources 2012; 208:96-119.

[11] Trogadas P, Fuller TF, Strasser P. Carbon as catalyst and support for electrochemical energy conversion. Carbon 2014; 75:5-42.

[12] Oezaslan M, Hasche F, Strasser P. Oxygen electroreduction on $\mathrm{PtCo}_{3}, \mathrm{PtCo}$ and $\mathrm{Pt}_{3} \mathrm{Co}$ alloy nanoparticles for alkaline and acidic PEM fuel cells. Journal of The Electrochemical Society 2012; 159(4):B394-405.

[13] Ge X, Sumboja A, Wuu D, An T, Li B, Goh FWT, Hor TSA, Zong Y, Liu Z. Oxygen reduction in alkaline media: From mechanisms to recent advances of catalysts. ACS Catalysis 2015; 5:4643-67.

[14] Tan JL, De Jesus AM, Chua SL, Sanetuntikul J, Shanmugam S, Tongol BJV, Kim H. Preparation and characterization of palladium-nickel on graphene oxide support as anode catalyst for alkaline direct ethanol fuel cell. Applied Catalysis A: General 2017; 531:29-35.
[15] Lima FHB, Salgado JRC, Gonzalez ER, Ticianelli EA. Electrocatalytic properties of PtCo/C and PtNi/ $C$ alloys for the oxygen reduction reaction in alkaline solution. Journal of the Electrochemical Society 2007; 154(4):A369-75.

[16] Zhao Y, Liu J, Zhao Y, Wang F. Compositioncontrolled synthesis of carbon-supported Pt-Co alloy nanoparticles and the origin of their ORR activity enhancement. Physical Chemistry Chemical Physics 2014; 16:19298-306.

[17] Gribov EN, Zinovieva AY, Voropaev IN, Simonov PA, Romanenko AV, Okunev AG. Activities of Pt/ Sibunit-1562 catalysts in the ORR in PEMFC: Effect of Pt content and Pt load at cathode. International Journal of Hydrogen Energy 2012; 37(16):11894-903.

[18] Cheng N, Kutz R, Kemna C, Wieckowski A. Enhanced ORR activity of cobalt porphyrin codeposited with transition metal oxides on Au and C electrodes. The ORR threshold data. Journal of Electroanalytical Chemistry 2013; 705:8-12.

[19] Liu H, Zhang L, Zhang J, Ghosh D, Jung J, Downing BW, Whittemore E. Electrocatalytic reduction of $\mathrm{O}_{2}$ and $\mathrm{H}_{2} \mathrm{O}_{2}$ by adsorbed cobalt tetramethoxyphenyl porphyrin and its application for fuel cell cathodes. Journal of Power Sources 2006; 161:743-52.

[20] Giner-Sanz JJ, Ortega EM, Pérez-Herranz V. Optimization of the electrochemical impedance spectroscopy measurement parameters for PEM fuel cell spectrum determination. Electrochimica Acta 2015; 174:1290-8.

[21] Wang M, Wang Q, Zhu W, Yang Y, Zhou H, Zhang F, Zhou L, Razal JM, Wallace GG, Chen J. Metal porphyrin intercalated reduced graphene oxide nanocomposite utilized for electrocatalytic oxygen reduction. Green Energy \& Environment 2017; 2:285-93.

[22] Sun Z, Li J, Zheng H, Liu X, Ye S, Du P. Pyrolyzed cobalt porphyrin-modified carbon nanomaterial as an active catalyst for electrocatalytic water oxidation. International Journal of Hydrogen Energy 2015; 40(20):6538-45. 